\title{
Unrevealing the Magic of Wonder Fruit: Vaccinium Macrocarpon
}

\author{
Research Article
}

\section{Himanshu Deswal1*, Amit Bhardwaj², Vidushi Sheokand³, Jasleen Kaur',}

1. Dental Officer, ECHS Polyclinic, Ropar, Punjab.

2. Professor and Head, Department of Periodontology, Faculty of Dental Sciences, SGT University, Gurgaon.

3. Reader, Department of Periodontology, Faculty of Dental Sciences, SGT University, Gurgaon.

4. Private practitioner.

\begin{abstract}
Vaccinium macrocarpon (cranberry) is a native fruit of northern America. It is a small evergreen shrub which grown in cooler climate of different parts of world. It is an abundant source of Vitamin and Minerals. It has potent health benefits which include its anti adhering property, anti oxidant property, UTI, gastrointestinal system, anti tumor effect as well as in oral diseases. It is more biocompatible and less noxious which makes it more potent therapeutic agent. This review is formed for displaying cranberry as a natural weapon against the medical and oral disease.
\end{abstract}

Key Words: Cranberry, Vaccinium macrocarpon, Urinary Tract Infection, Periodontal disease, Oral infection, Cancer.

\section{Introduction}

Vaccinium macrocarpon is the Latin name of the Crain berry plant.(1) The name cranberry is procure from craneberry, as it resembles to head neck and bill of crane.(2)

\section{Habitat}

It is extensively cultivated in cooler climes of the north Europe, north America, north asia and canada. In United States, New Jersey, Oregon, Wisconsin, British Columbia, Washington, Prince Edward Island etc. they are cultivated. Wisconsin and British Columbia are the leading producers. It is also cultivated in Argentina, Netherlands and Chile. They are planted between April to May, October, early November.(2)

\section{Botanical Name}

Kingdom : plantae

Clade : Tracheophytes

Clade : Angiosperms

Clade : Eudicots

Clade : Asterids

Order : Ericales

Family : Ericaceae

Genus : Vaccinium

Subgenus : Oxycoccus

Species : Vaccinium macrocarpon(2)

* Corresponding Author:

\section{Himanshu Deswal,}

Dental Officer, ECHS Polyclinic,

Ropar, Punjab. India.

Mail Id: deswal1706@gmail.com
Types

1. Vaccinium macrocarpon (large cranberry, American cranberry),

2. Vaccinium microcarpom (small cranberry),

3. Vaccinium oxycoccus (common cranberry or northern cranberry),

4. Vaccinium erythrocarpum (southern mountain cranberry)(3)

Among these types of cranberry Vaccinium macrocarpon has most beneficial effects which has been proven since ancient times.

\section{Composition}

It consist of $80 \%$ water and $10 \%$ carbohydrates, (4) while the other $10 \%$ are flavonoids, Anthocyanins, catechins, proanthocyanins, triterpenoids, organic acids and ascorbic acid.(5) Citric acid, gallic acid, quinic acid, also a lesser content of benzoic acid and glucuronic acid are the organic acids present in it along with organic acid vitamins such B2, B3, B6, A, C, E, K and minerals such as calcium, Sodium, Zinc, magnesium, phosphorus, iron, potassium. It also contains. phenolic acids like hydroxycinnamic acid including cinnamic, coumaric, caffeic and ferocious acid and hydroxybenzoic acid including vanillic acid.(2)

\section{Description}

Cranberry is an evergreen plant of North America. They are four meter shrubs having a flower which is dark pink in colour and have purple spike at center. They also have reddish black berries. Root length is approx 4 to 6 inches and for nutrients supply it depends on mycorrhizal association.(2) 


\section{Available forms}

1. Fresh fruits(2)

2. Dry fruits(4)

3. Frozen fruit(2)

4. $\operatorname{Jams}(4)$

5. Concentrate(2)

6. Tablets(6)

7. Powders (6)

8. Juice(7)

\section{Biological properties}

\section{UTI}

In urinary tract infection uropathogens enter into urinary tract, it mainly affects urinary bladder as microorganism invade via urethra. Female are more prone to UTI than male. If left untreated it can pervade towards kidney. Microorganism level crosses the threshold limit in urine it leads to Urinary Tract Infection.(6) Some of symptoms include frequency, supra pubic pain, dysuria, urgency, hematuria, nausea, cloudy urine, vomiting, delirium etc.(2) Cranberry is one of the traditional medicine which is used to treat UTI. Its extract has antibacterial activity against uropathogens i.e. Escherichia coli, Enterobacter aerogenes, Klebsiella pneumonia and Staphylococcus aureus.(8) It curtail the formation of biofilm on the uroepithelial cells.(9) It consist of proanthocyanidins which has anti clinging property, which constrain adherence of bacteria to uroepithelial cells,(10) which is essential if bacteria is to cause infection.(11)

\section{Mechanism of action}

1. Kinney proposed another mechanism of action that cranberry juice contains quinic acid which increases the excretion of hippuric acid in the urine which is said to have antibacterial effect, thus preventing the infection.(12) But this however is not accepted as it is not proved.

2. Cranberry juice which contains fructose which prevents the adherence of fimbriated E-Coli to the uroepithelial cells.(13)

3. Cranberry juice may affect the concentration of Tamm-Horsfall Glycoproteins or Uromodulin in urine which hinders Escherichia coli as well other bacteria bind to the human kidney.(14)

4. Non-enzymatic production of nitric oxide under acidic conditions. Nitric oxide can become activated via bacterial nitrate reductase and the induction of inflammation-driven nitric oxide synthase. This in turn could potentially create a bacteriostatic environment within the urinary tract.(15)

Cranberry juice acts beneficial in preventing infection instead of treating the UTI as it has less effect on microorganism after adhesion.(2)

\section{GIT}

Helicobacter pylori is a gram negative bacteria resides in the stomach and duodenum of human. It induces inflammatory reaction of the stomach mucosa which may be leads to stomach cancer, peptic ulcer, mucosa-associated lymphoid tissue lymphoma and idiopathic thrombocytopenic purpura. Growth of Helicobacter pylori was suppressed by Cranberry extract. When use in combination with other food products or probiotics it is believed to cause more elimination of the H.pylori.(16) Extract constrains the attachment of bacteria to gastric cells.(17) It is efficacious against Bacillus cereus and Clostridium perfringens.

Dissolution of the gram negative bacteria leads to release of lipopolysaccharides which is present in the outer membrane of the bacteria. This leads to cell death due to Permeability of the cell and leakage of cell content. Lipopolysaccharies from Salmonella typhimurium and Salmonella infantis releases by cranberry extract.(18)

Antimicrobial property of cranberry extract is due to gallic acid which destabilizes the membrane of bacteria by chelating divalent cations. $(18,19)$ Biosynthesis of cell wall of Staphylococcus aureus is interrupted by the anti microbial property of cranberry extract. Cranberry extract when use in combination with $\beta$-lactam antibiotic shows synergetic effect in treating $\mathrm{S}$. aureus infections.(20)

Cranberry extract contains proanthocyanidins which is active in colon due to which it binds to bacterial receptor of colon and hinders its binding with uroepithelial cells and inhibit its multiplication.(21)

\section{Cardiovascular health}

Cranberry contains flavonoids which are potent antioxidant and reduces the chance of atherosclerosis. Deposition of fat, cholesterol and calcium in the arteries, due to which arteries become narrow this leads to a disease called atherosclerosis. Oxygen rich blood found difficulty in reaching other body parts which can leads to strokes and heart attacks.(1)

\section{Bones}

Cranberries are the abundant source of calcium. Regular intake of cranberry juice, it enhances the strength of bones.(1)

\section{Scurvy}

Deficiency of Vitamin C leads to a disease called scurvy. Cranberry juice is an abundant source of Vitamin C. Regular intake of cranberry juice impede scurvy.(1) 


\section{Obesity}

Cranberry juice is a copious source of organic acid. Organic acid has emulsification effect on the fat accumulated. So, it's good for obese people.(1)

\section{Anti-Aging}

Cranberry juice contains phytonutrients and many antioxidants. They play an important role in skin protection. Anti oxidant present in cranberry reduces free radicals which enhances its anti aging property.(1)

\section{Anti-Oxidant}

Intake of doxorubicin drug leads to cardiotoxicity by forming free radicals. The free radicals enhance the oxidative stress which causes cardiac failure is resisted by cranberry extract. Cranberry extracts are abundant source of phenoloic acid and flavonoids as these compounds have potent antioxidant effect,(22) they restrict oxidative process in different cells and tissues.(23)

\section{Anti-Tumor Effect}

Among all berries cranberry has highest Anti oxidant property. The oxidative process associated with tumor genesis is restrained with the help of cranberry's anthocanins antioxidant property.(5) Cranberry proanthocyanidin (PAC) treatment for human oesophageal adenocarcinoma restrains the various carcinogenic linked processes. PAC treatment increasing the response of $\mathrm{BH} 3$ interacting domain death antagonist, TRADD and TP73 which enhances apoptosis.(24)

PAC induces restrain of ornthine decarboxylase in epithelial cells.(25) Cranberry contains Ursolic acid which restrains the growth of leukemia cell lines and lung carcinoma.(26) PAC treatment has remarkably controlling influence on cancer related biological processes and plays an important role in communicating pathways in NCI-H460 lung cancer cells. PAC has extensively remarkable and rapid apoptosis inducing effects on multiple cell cycle linked genes resulting in decreased cell multiplication and enhanced apoptosis. (27)

Cranberry extracts which remarkably reduce the cell growth and escalation of oral squamous cell carcinomas. There was a sudden rise of mRNA expression in caspases-2, caspases-8, apoptosis initiator, and effector. The extract also declines cellular adhesion. (28)

In prostate cancer, whole cranberry extract initiate cytotoxicity, which restrains the expression of cell cycle proteins and regression of DU145 cells through the cell cycle.(29) Proanthocyanidins restrain the expression of matrix metalloproteinase in DU145 cells and decrease translocation of NFkB p65 protein to nucleus.(30)
Figure 2: Cranberry proanthocyanidins showing the presence of A-type linkages

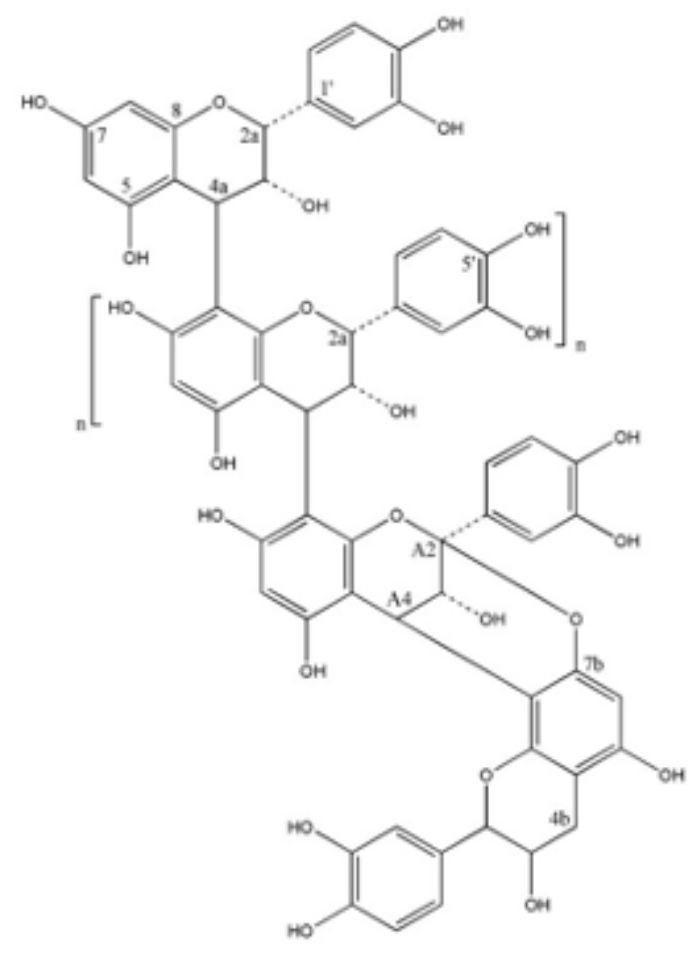

\section{Lung Inflammation}

Inflammation in lungs which is caused by influenza virus is cured effectively by the cranberries anti inflammatory property. NDM or non dialyzable material restrains influenza virus from attaching to the cells and restricts the flu infection.(1)

\section{Interactions}

Few exceptions were there instead of abundant health benefits which are listed below.

\section{Warfarin (Coumadin):}

Warfarin is an anticoagulant drug. Its action is by reducing the clot formation in the body.

Those people who consume Warfarin in cardiovascular disorders should be very cautious regarding consumption of cranberries as there are more chances of bleeding.

\section{Aspirin allergy}

Cranberries are a good source of salicylic acid, aspirin also contains salicylic acid. Person consumes blood thinner they should avoid taking cranberry juice. If people are allergic to aspirin, should avoid Cranberries.

\section{Kidney stones}

Cranberry juice contains the abundant amount of oxalate and calcium. Oxalate and calcium are of great chances of developing the calcium oxalate stones 
and uric acid stones in some people. People having a history of kidney stones then they should avoid consumption of the cranberry supplements or berry juice.(1)

\section{Dental Uses \\ A. Dental caries}

Enzymes, polysaccharides, host and bacteria comprise biofilm, whose progression and initiation leads to the oral disease.(31) In the oral environment when sucrose level is high, Streptococcus mutans initiate the genes which are liable for its virulence. Genes (gtfB, gtfC, gtfD) which are liable for the streptococcus mutans virulence decodes glucosyltransferase and formed glycans when combine with sucrose.(32) In the existence of glucosyltransferase sucrose form glycan which imbibe to the surface. This leads to aggregation of the bacteria on the tooth surface and form bulk and structure of biofilm. After adherence of streptococcus mutans to the tooth surface leads to production of acid which results in demineralization of the enamel and it leads to dental caries.

In the plaque matrix acid is produced by bacteria which leads to acid resistant bacteria.(7) Anti clinging property of cranberry restrains the attachment of cariogenic bacteria on the surface of tooth.(33)

It restrains the bacteria from clinging on the surface of tooth which regulates oral flora but does not destroy them. Ervin I. Weiss et al conducted a study in which there is significant reduction in bacterial count (streptococcus mutans and total bacteria) in the volunteer's saliva, using cranberry extract mouthwash as compared to placebo mouthwash.(33)

\section{B. Fungal growth}

Candidiasis is fungal infection which occur due to profound growth of the Candida albicans.

A-type Cranberry proanthocyanidin (AC-PAC) diminish the attachment of $\mathrm{C}$. albicans to oral epithelial cells.

It also leads to great reduction in the secretion of cytokines, hence curtail inflammation. In the prevention and treatment of oral candidiasis AC-PAC can be used.(34)

\section{Perioodontal disease}

Resorption of alveolar bone is a typical hallmark of periodontal disease. Reduction in the osteoclastic activity as well as reduction in the formation of differentiated osteoclast is by the cranberry extract. It also hampers the physiology of bone matrix. In the prevention and treatment of bone loss related to inflammatory disorders such as periodontal disease cranberry extract may be used.(35) Cranberry extracts decrease the periodontopathogens induced inflammation by decreasing the inflammatory cytokines like IL-1 $\beta$, IL-6, and IL-8 and TNF- $\alpha .(36)$

\section{Conclusion}

Unlike other medicines vaccinium macrocarpon is a natural weapon against many ailments which can be consumed regularly and also be cautious about its interactions. Cranberry extracts has tremendous health benefits by its anti adherence property and also by anti oxidant property which acts as potent alternative to the cancer treatment, UTI, Gastrointestinal system and oral disease. It helps in ameliorating the overall health and shield them from illness. Further research should be conducted in elaborating the properties of this wonder fruit.

\section{References}

1. Sujana K, Tejaswini KS, Lakshmi SS. Cranberry fruit: An update review. International Journal of Herbal Medicine 2016;4(3):5-8.

2. Srinidhi AK. Cranberry and its Antibacterial Activity - A Review . J Pharm Sci \& Res 2014;6(1):41 - 4.

3. Philip N, Walsh LJ. Cranberry Polyphenols: Natural Weapons against Dental Caries. Dent J (Basel) 2019;7(1):20.

4. Lenter C. Geigi scientific tables. 8th Ed. West Caldwell, NJ: CIBA Geigy, 1991.

5. Neto CC. Cranberry and Its Phytochemicals: A Review of In Vitro Anticancer Stiudies. J Nutr 2007;137(1):186S- 193S.

6. Jepson RG, Williams G, Craig JC. Cranberries for preventing urinary tract infections. Cochrane Database Syst Rev 2012 Oct;2012(10):CD001321.

7. Gregoire S, Singh AP, Vorsa N, Koo H. Influence of cranberry phenolics on glucan synthesis by glucosyl transferases and Streptococcus mutans acidogenicity. Journal of Applied Microbiology. 2007;103(5):1960-1968.

8. Rahbar M and Diba K. In vitro activity of cranberry extract against etiological agents of urinary tract infections. Afr J Pharm Pharmacol 2010;4(5):286-288.

9. Cimolai $\mathrm{N}$ and Cimolai $\mathrm{T}$. The cranberry and the urinary tract. Eur J Clin Microbiol 2007;26(11):767-776.

10. Sobota AE. Inhibition of bacterial adherence by cranberry juice. Potential use for treatment of urinary tract infections. J Urol 1984; 131(5): 1013-1016.

11.Brinckmann J, Wollschlaeger B. Cranberry. In: Blumenthal $\mathrm{M}$, ed. The ABC Clinical Guide to Herbs. Austin: American Botanical Council, 2003; 76-83.

12.Kinney AB, Blount M. Effect of cranberry juice on urinary pH. Nursing Research 1979; 28(5): 287-290.

13.Zafriri D, Ofek I, Adar R, Pocino M, Sharon N. Inhibitory Activity of Cranberry Juice on Adherence of Type 1 and Type P Fimbriated Escherichia coli to Eucaryotic Cells. Antimicrobial Agents and Chemotheraphy 1989;33(1):92-98.

14.Dulawa J, Jann K, Thomsen M, Rambausek M, Ritz E. Tamm-Horsfall glycoprotein interferes with bacterial adherence to human kidney cells. Eur. J. Clin. Invest. 1988;18(1):87-91.

15. Vasileiou I, Katsargyris A, Theocharis S, Giaginis C. Current clinical status on the preventive effects of cranberry consumption against urinary tract infections. Nutr Res. 2013;33(8):595-607. 
16.Matsushima M, Suzuki T, Masui A, Kasai K, Kouchi T, Takagi A et al. Growth inhibitory action of cranberry on Helicobacter pylori. J Gastroenterol Hepatol 2008;23(2):S175-S180.

17.Burger O, Weiss E, Sharon N, Tabak M, Neeman I, Ofek I.Inhibition of Helicobacter pylori adhesion to human gastric mucus by a high-molecular-weight constituent of cranberry juice. Crit Rev Food Sci Nutr 2002;42(3Suppl):279- 84 .

18.Nohynek L, Alakomi HL, Kahkanen M, Heinonen M, Helander IM, Oksman-Caldentey KM, Puupponen- Pimia R. Berry phenolics antimicrobial properties and mechanisms of action against severe human pathogens. Nutr Cancer 2006; 54(1):18-32.

19. Vattem DA, Lin YT, Labbe RG, Shetty K. Phenolic antioxidant mobilization in cranberry pomace by solid-state bioprocessing using food grade fungus Lentinus edodes and effect on antimicrobial activity against select food borne pathogens. Innov Food Sci Emerg Technol 2004;5(1):81-91.

20.Diarra MS, Block G, Rempel H, Oomah BD, Harrison J, McCallum J, Boulanger S, Brouillette E, Gattuso M, Malouin F. In vitro and in vivo antibacterial activities of cranberry press cake extracts alone or in combination with $\beta$-lactams against Staphylococcus aureus. BMC Complement Altern Med 2013(4);13:90.

21.Harmand MF and Blanquet P. The fate of total flavonolic oligomers (OFT) extracted from Vitis vinifera L. in the rat. European Journal of Drug Metabolism and Pharmacokinetics 1978; 1:15-30.

22.Elberry AA, Abdel-Naim AB, Abdel-Sattar EA, Nagy AA, Mosli HA, Mohamadin AM, Ashour OM. Cranberry (Vaccinium macrocarpon) protects against doxorubicin-induced cardiotoxicity in rats. Food Chem Toxicol 2010; 48(5): 1178-84.

23. Willet WC. Diet, nutrition, and avoidable cancer. Environ Health Perspect 1995;103(8):165-170.

24.Tewari A.. A cranberry proanthocyanidin inhibits cancer-related processes in human oesophageal adenocarcinoma cells. Senior Honours Thesis, the Ohio State University. 2006.

25.Kandil FE, Smith MAL, Rogers RB, Pepin M-F, Song LL, Pezzuto JM, Seigler DS. Composition of a chemopreventive proantho-cyanidin-rich fraction from cranberry fruits responsible for the inhibition of TPA induced ODC activity. J Agric Food Chem. 2002; 50(3): 1063-1069.

26.Wang M, Li J, Shao Y, Huang TC, Huang MT, Chin CK, Rosen RT, Ho CT. Antioxidative and cytotoxic components of high bush blueberry (Vaccinium corymbosum L.) in phytochemicals and phytopharmaceuticals. Champaign, IL: AOCS Press; 2000, 271-277.
27.Kresty LA, Howell AB, Baird M. Cranberry Proanthocyanidins Mediate Growth Arrest of Lung Cancer Cells through Modulation of Gene Expression and Rapid Induction of Apoptosis. Molecules 2011; 16(3): 2375-2390.

28.Chatelain K, Phippen S,McCabe J, Teeters CA, O'Malley S, Kingsley K. Cranberry and grape seed extracts inhibit the proliferative phenotype of oral squamous cell carcinomas. Evid Based Complement Alternat Med. 2011;2011:467691.

29.Deziel B, MacPhee J, Patel K, Catalli A, Kulka M, Neto $\mathrm{C}$ et al. American cranberry (Vaccinium macrocarpon) extract affects human prostate cancer cell growth via cell cycle arrest by modulating expression of cell cycle regulators. Food Funct 2012; 3(5): 556-64.

30.Déziel BA, Patel K, Neto C, Gottschall-Pass K, Hurta RA. Proanthocyanidins from the American cranberry (Vaccinium macrocarpon) inhibit matrix metalloproteinase-2 and matrix metalloproteinase-9 activity in human prostate cancer cells via alterations in multiple cellular signalling pathways. J Cell Biochem 2010; 111(3): 742-754.

31.D'dharan SR, Neelakantan P. Therapeutic Uses of Cranberry (Vaccinium Macrocarpon) Extract - A Review. International Journal of Pharmacognosy and Phytochemical Research September-November 2013;5(3):197-199.

32. Yoo S, Murata RM, Duarte S. Antimicrobial Traits of Tea- and Cranberry-Derived Polyphenols against Streptococcus mutans. Caries Res 2011; 45(4):327335 .

33.Ervin I. Weiss, Avital Kozlovsky, Adorno Steinberg, Ron Lev-Dor, Ronit Bar Ness Greenstein et al. A high molecular mass cranberry constituent reduces mutans streptococci level in saliva and inhibits in vitro adhesion to hydroxyapatite. FEMS Microbiology Letters. 2004; 232(1):89-92.

34.Feldman M, Tanabe S, Howell A, Grenier D. Cranberry proanthocyanidins inhibit the adherence properties of Candida albicans and cytokine secretion by oral epithelial cells. BMC Complement Altern Med 2012;12:6.

35. Tanabe S, Santos J, Vu DL, Howell AB, Grenier D. A-type cranberry proanthocyanidins inhibit the RANKL-dependant differentiation and function of human osteoclasts. Molecules 2011; 16(3): 2365-2374.

36. Bodet C, Chandad F, Grenier D. Anti-inflammatory activity of a highmolecular weight cranberry fraction on macrophages stimulated by lipopolysaccharides from periodontopathogens. J Dent Res. 2006; 85(3): 235-239. 